\title{
Effect of Ceramic Powder Coatings on Low Carbon Steel
}

\author{
Oluwatoyin Adenike Olaseinde, Benjamin Omotayo Adewuyi \\ Department of Metallurgical and Materials Engineering, Federal University of Technology, Akure, Nigeria \\ Email: adenikeseinde@yahoo.com
}

Received 24 April 2016; accepted 2 May 2016; published 5 May 2016

Copyright () 2016 by authors and Scientific Research Publishing Inc.

This work is licensed under the Creative Commons Attribution International License (CC BY).

http://creativecommons.org/licenses/by/4.0/

(c) (i) Open Access

\begin{abstract}
Effect of ceramic powder coating on low carbon steel samples was presented. Electrostatic deposition method was used to produce ceramic coatings on low carbon steels. The coatings were fabricated over a range of temperatures $\left(100^{\circ} \mathrm{C}-400^{\circ} \mathrm{C}\right)$. Detailed investigation on the corrosion behaviour, the hardness property and electrode potential of the fabricated and uncoated samples are reported. The ceramic materials used are locally available in Ondo-State Nigeria. The coating temperatures affect the rate of corrosion, the hardness property and the electrical resistivity of the coated steel sample. The sample coated at $300^{\circ} \mathrm{C}$ with ceramic powder $Y$ showed the best corrosion resistance in $0.5 \mathrm{M} \mathrm{NaCl}$ solution. The highest resistivity occurred in the sample coated at $300^{\circ} \mathrm{C}$ with ceramic powder $\mathrm{Z}$. All the samples coated with ceramic powder $\mathrm{Y}$ had better corrosion resistance in $0.5 \mathrm{M} \mathrm{NaCl}$ than the one coated by sample $\mathrm{Z}$.
\end{abstract}

\section{Keywords}

\section{Steel, Corrosion, Coating, Ceramic}

\section{Introduction}

There has been a lot of interest on production of advanced material for technological uses. Although, much has been done by producing new alloys with improved properties, there is a limit to the protection that can be afforded by this means alone. For this reason coatings have played an increasing role in protecting the structural metals from stress and corrosion [1].

Coatings played an important role in corrosion control, used either alone or as part of overall strategy of corrosion control. While theoretically, coatings may be employed in a variety of ways to modify, hinder or thwart the corrosion reaction [2]. Various conventional methods such as carburizing, nitriding, electroplating are used over a century to protect tools; however, the development of the hard protective coatings in the narrower sense, started in the sixties with the discovery of chemical vapour deposition and physical vapour deposition tech- 
niques [3]. In recent times, modern deposition techniques such as thermal spray and laser cladding have become more popular and give large throughput in shortest possible time [4]. Thermal spraying as a convenient way has been reported by several researchers. Thermal spraying offers an effective and economic way to make the coating without affecting any other properties of the component [5]. Metal bars, wires, and sheets require protective coatings to prolong their use on exposure to service environments wherein they inevitably encounter corroding species and conditions conducive to the initiation of rust [6]. The advantage of the process of electrostatic coating is the capability to recover the little over-spray and also the procedure reduces cost. Electrostatics reduces considerably the amount of coating fluid needed for thorough protection in comparison with non-electrostatic methods. Ceramics are solid articles whose composition and essential components are inorganic non-metallic materials [7]. Inorganic coatings are applied to metals and to some other materials to protect and modify the surface properties like the resistance to abrasion, erosion, shock, oxidation, corrosion, chemical reaction, diffusion, control of hardness, texture, smoothness, lubrication, heat transfer by conduction and radiation, electrical resistance, magnetic properties, thermionic performance and heat insulation \& ablation [8]. Powder coatings are widely used for protection of pipelines in oil industries. Corrosion is a major issue for the increase of service life and reliability of metallic materials [9]. The porosity of the $\mathrm{Cr}_{3} \mathrm{C}_{2}-\mathrm{NiCr}$ coatings as reported by authors lies in the range of $1 \%-3.5 \%$, which is found to be useful in developing hot corrosion resistance in boiler tube steel [10]-[12]. The low value of porosity might be due to high kinetic energy of the powder particles. The dense coatings are supposed to provide very good corrosion resistance as compared to porous coatings, as porosities are the preferential corrosion paths through which the corrosive species can penetrate the coatings to reach the substrate and may cause rapid corrosion attack [12]-[14]. Thicker coatings permit the pass of the electrolyte due to the stresses generated during coating deposition and the corresponding crack formation between different layers. Thinner coated samples let the electrolyte go through the Coating Substrate and erosion-corrosion behaviour of coating because it is not thick enough to correctly protect the base steel. Optimization of spraying parameters and stress relaxation processes will be as important as thickness when protection of the base steel is needed with cermet coatings [15]. The effect of coating of low carbon steel by locally available ceramic materials in Nigeria was investigated.

\section{Experimental}

The steel used is a low carbon steel sheet with carbon content of $0.2-0.3 \mathrm{wt} \%$ and total alloying content of 5 $w t \%$. Two different types of ceramic material were locally sourced (ceramic powder $Y$ coating and ceramic powder $\mathrm{Z}$ coating). The phase analysis of the ceramic powder was carried out using $\mathrm{x}$-ray diffractometer (XRD) at Engineering Material Development Institute (EMDI) centre, Akure, Ondo State, Nigeria.

The steel used is a low carbon steel sheet with carbon content of $0.2-0.3 \mathrm{wt} \%$ and total alloying content of 5 $w t \%$. Two different types of ceramic material were locally sourced (ceramic powder $Y$ coating and ceramic powder $\mathrm{Z}$ coating). The phase analysis of the ceramic powder was carried out using $\mathrm{RC}$ mini diffractometer MD-10, x-ray diffractometer (XRD) at Engineering Material Development Institute (EMDI) Centre, Akure, Ondo State, Nigeria.

The surface of steel was grinded to a mirror like surface using the polishing machine to provide uniform or levelled surface for deposition of ceramic powder. The chemical composition of the steel sample was determined by mass spectrometry. The Sieve analysis of the ceramic materials with sieves of $212 \mu \mathrm{m}, 150 \mu \mathrm{m}, 105$ $\mu \mathrm{m}$ and $75 \mu \mathrm{m}$ were carried out. Binder was first applied on the low carbon steel substrate using brush, followed by the electrostatic deposition of the ceramic powder Y and ceramic powder Z. After the coating, the powder coated products were placed in an electric oven where the coated materials and heat chemically reacts. Suitable adhesion was observed between the temperatures of $300^{\circ} \mathrm{C}-410^{\circ} \mathrm{C}$ for ceramic powder $\mathrm{Y}$, while for the ceramic powder $Z$, the adhesion was observed at $110^{\circ} \mathrm{C}-410^{\circ} \mathrm{C}$.

The corrosion tests were carried out by immersing the samples in $0.5 \mathrm{M} \mathrm{NaCl}$ for the period of 30 days. The electrode potential, $\mathrm{pH}$, and change in weight of each sample was taken and recorded against exposure time.

Zinc electrode was used as the reference electrode. Hardness test was carried out on the material and the resistivity of the powder coated samples was also studied.

\section{Results and Discussion}

The XRD result of ceramic powder Y showed the powder to consist mainly of sodium aluminium silicate hy- 
droxide and sodium Beryllium Aluminium Silicate hydroxide, while ceramic powder Z consists mainly of Calcium Aluminium Silicate hydroxide and magnesium Aluminium Silicate hydroxide (Table 1).

The different temperatures at which the samples were coated are shown below.

The two locally sourced ceramic powders are labelled as $\mathrm{Y}$ and $\mathrm{Z}$.

$$
\begin{aligned}
& \mathbf{A}=\text { Sample coated at } 100^{\circ} \mathrm{C} \text { with } \mathrm{Y} \\
& \mathbf{B}=\text { Sample coated at } 200^{\circ} \mathrm{C} \text { with } \mathrm{Y} \\
& \mathbf{C}=\text { Sample coated at } 250^{\circ} \mathrm{C} \text { with } \mathrm{Y} \\
& \mathbf{D}=\text { Sample coated at } 300^{\circ} \mathrm{C} \text { with } \mathrm{Y} \\
& \mathbf{E}=\text { Sample coated at } 350^{\circ} \mathrm{C} \text { with } \mathrm{Y} \\
& \mathbf{F}=\text { Sample coated at } 400^{\circ} \mathrm{C} \text { with } \mathrm{Y} \\
& \mathbf{G}=\text { Sample coated at } 250^{\circ} \mathrm{C} \text { with } \mathrm{Z} \\
& \mathbf{H}=\text { Sample coated at } 300^{\circ} \mathrm{C} \text { with } \mathrm{Z} \\
& \mathbf{I}=\text { Sample coated at } 350^{\circ} \mathrm{C} \text { with } \mathrm{Z} \\
& \mathbf{J}=\text { Sample coated at } 400^{\circ} \mathrm{C} \text { with } \mathrm{Z} \\
& \mathbf{K}=\text { Uncoated reference sample }
\end{aligned}
$$

There were blackish spots that spread itself across the surface of the steel sheet coated with ceramic powder Y coating and the finer the ceramic materials, the easier the coating. Flat sheet with about $0.05 \mathrm{~mm}$ were coated. The thickness of the steel material that could be coated varied with the ceramic powder particle size, consequently flat sheet with small thickness were coated. At a temperature below $100^{\circ} \mathrm{C}$ and above $400^{\circ} \mathrm{C}$ the adherence of the ceramic powder $Y$ to the surface of the steel was not observed. Also, adherence of ceramic powder $\mathrm{Z}$ to the surface of the steel was observed to occur only at a temperature range of $250^{\circ} \mathrm{C}$ to $400^{\circ} \mathrm{C}$.

Figure 1 shows low carbon steel microstructure indicating the presence of ferrite phase and pearlite phase. The thick light layers are ferrite phase. Brown deposit appears on the surface of steel coated with ceramic powder Z (Figure 2). The microstructure of ceramic powder Y coating on steel appears as a black coated layer (Figure 3). The adherence of the ceramic powder on the steel substrate was seen on the micrograph.

\subsection{Hardness Test}

The highest hardness value for coated steel was observed at $100^{\circ} \mathrm{C}$ for sample coated with Y (Figure 4). The higher value was because the ball of the hardness testing machine used could penetrate it easily to reach the steel,

Table 1. Phase analysis of the ceramic powder $\mathrm{Y}$ and $\mathrm{Z}$.

\begin{tabular}{cc}
\hline Table & Phases \\
\hline Y & Sodium Aluminium Silicate. \\
Z & Sodium Berylium Silicate hydroxide. \\
Calcium aluminium silicate hydroxide. \\
Magnesium aluminium silicate hydroxide.
\end{tabular}

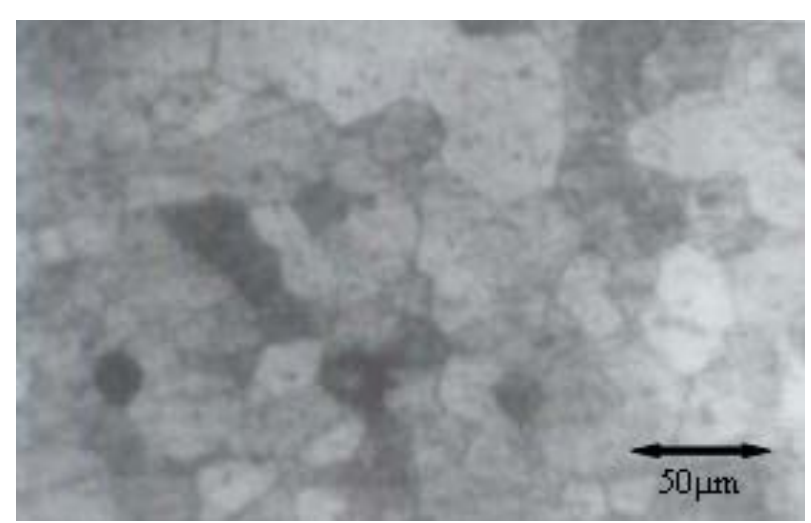

Figure 1. Optical micrograph of the uncoated sample. 


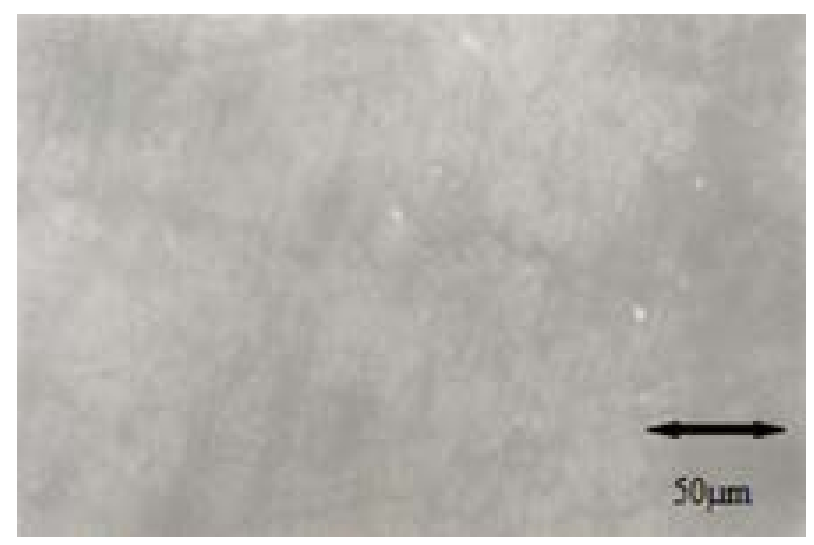

Figure 2. Optical micrograph of sample coated with ceramic powder Z.

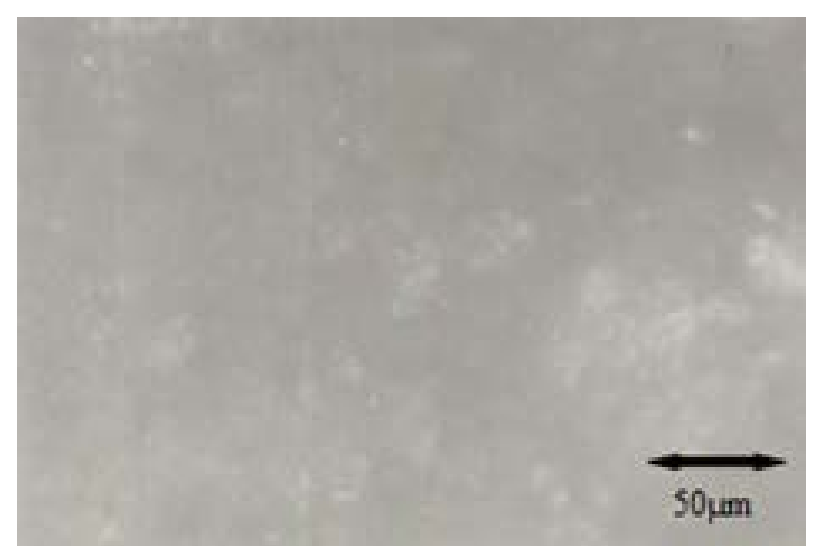

Figure 3. Optical micrograph of steel sample coated with ceramic powder Y.

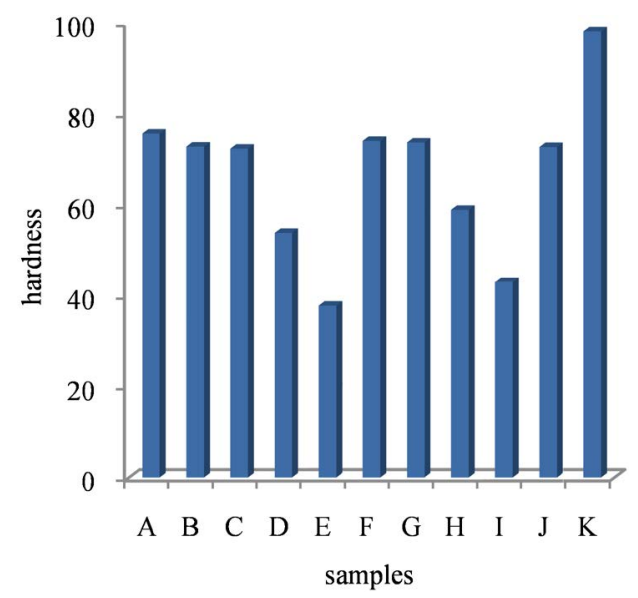

Figure 4. Hardness value of the samples.

when compared with sample at $200^{\circ} \mathrm{C}$ which shows a higher resistance hence a lower hardness value. Therefore it should be noted that the lower the hardness value, the higher the hardness of the ceramic coating. Higher values of hardness for the coatings may be due to the high density and cohesive strength of the individual splats as a result of the high impact velocity of the coating particles as suggested by Sidhu TS et al. [13] and Verdon C et al. [16]. 
As the coating temperature increases, the hardness value decreases and hence an increase in the hardness properties of the ceramic coating. Putting all samples coated with the ceramic powders into consideration. The steel coated at $350^{\circ} \mathrm{C}$ with ceramic powder $\mathrm{Z}$ had the highest hardness with the lowest hardness value. The ceramic powder coated steel at $350^{\circ} \mathrm{C}$ for both $\mathrm{Y}$ and $\mathrm{Z}$ had the lowest hardness value; this showed that the ceramic powder adhered strongly to the surface of the steel.

\subsection{Resistivity Determination of Ceramic Coated Steel and Uncoated Steel Sheet}

Resistance of a material is directly proportional to its resistivity. The samples protected showed higher values of resistivity from $0.11 \Omega \mathrm{m}-0.39 \Omega \mathrm{m}$ and resistance from $1.48 \Omega \mathrm{m}-5.37 \Omega \mathrm{m}$ to the flow of current with respect to the uncoated sample $\mathrm{K}$ with $0.043 \Omega \mathrm{m}$ and $0.619 \Omega \mathrm{m}$ respectively (Table 2). Since the coated samples showed higher resistance to the flow of current, it implies that the rate of corrosion of the coated sample is lower than that of the uncoated sample. The higher current flow in the uncoated sample indicates a higher corrosion rate. For the sample coated at $400^{\circ} \mathrm{C}$ with ceramic coating $\mathrm{Z}$, higher current value was also observed which showed that the coating did not adhere much on the surface. The highest initial resistance to current was observed for the sample coated with $\mathrm{Z}$. The sample coated with ceramic material $\mathrm{Z}$ had the highest resistance to current at $250^{\circ} \mathrm{C}, 300^{\circ} \mathrm{C}$ and $350^{\circ} \mathrm{C}$ which are $5.286 \Omega, 5.373 \Omega$ and 5.094. The optimum resistance to current for samples coated with $\mathrm{Y}$ was observed at $200^{\circ} \mathrm{C}$ being $5.238 \Omega$. The optimum resistance value for the samples coated with the two powders was obtained at $300^{\circ} \mathrm{C}$ for sample coated with $\mathrm{Z}$. The resistance and resistivity value are $5.373 \Omega$ and $0.387 \Omega \mathrm{m}$ respectively.

\section{Electrode Potential Test}

The electrode potential values obtained in the course of the research work were discovered to vary with temperature. Results showed that higher positive values of electrode potential indicated higher resistance to corrosion rate [17].

With reference to Figure 5; it was noted that throughout the 30 days of exposure to the $0.5 \mathrm{M}$ sodium chloride solution, the electrode potential value of the steel coated at $100^{\circ} \mathrm{C}$ with ceramic coating $\mathrm{Y}$ was high compared to the uncoated sample, the highest value being $-128 \mathrm{mV}$ while the lowest value being $-453 \mathrm{mV}$. A maximum value of $-110 \mathrm{mV}$ and a minimum value of $-456 \mathrm{mV}$ was observed throughout the 30 days of exposure for the sample coated with ceramic coating $\mathrm{Y}$ at $200^{\circ} \mathrm{C}$. This value is also considerably high with reference to the uncoated sample and close to that of the sample coated at $100^{\circ} \mathrm{C}$. For the sample coated at $250^{\circ} \mathrm{C}$, the electrode potential value ranged from a maximum value of $-115 \mathrm{mV}$ to a minimum value of $-428 \mathrm{mV}$ which also signified higher resistance to the corrosion rate. The electrode potential values vary from a maximum value of $-114 \mathrm{mV}$

\begin{tabular}{|c|c|c|c|}
\hline Sample & Current (A) & Resistance $(\Omega)$ & Resistivity $(\Omega \mathrm{m})$ \\
\hline A & 0.17 & 4.6235 & 0.3330 \\
\hline B & 0.16 & 5.2375 & 0.3772 \\
\hline $\mathrm{C}$ & 0.17 & 4.9588 & 0.3572 \\
\hline $\mathrm{D}$ & 0.17 & 4.9824 & 0.3589 \\
\hline $\mathrm{E}$ & 0.16 & 4.9936 & 0.3597 \\
\hline $\mathrm{F}$ & 0.19 & 4.4842 & 0.3230 \\
\hline G & 0.16 & 5.2875 & 0.3808 \\
\hline $\mathrm{H}$ & 0.15 & 5.3733 & 0.3870 \\
\hline I & 0.16 & 5.0938 & 0.3668 \\
\hline $\mathrm{J}$ & 0.54 & 1.481481 & 0.1067 \\
\hline $\mathrm{K}$ & 0.73 & 0.609589 & 0.0439 \\
\hline
\end{tabular}




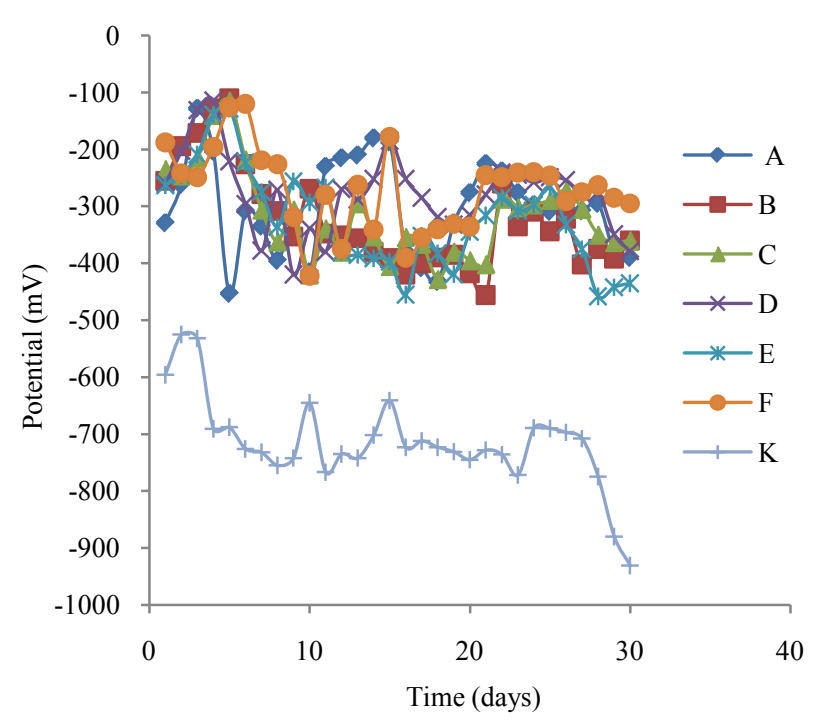

Figure 5. The graph of potential with time of steel sheet coated with ceramic sample $\mathrm{Y}$ with uncoated sample in $0.5 \mathrm{M}$ $\mathrm{NaCl}$ solution.

and a minimum value of $-420 \mathrm{mV}$ for sample coated at $300^{\circ} \mathrm{C}$. This give a narrower range when compared with other coating temperatures used. The electrode potential value falls with the range of $-128 \mathrm{mV}$ being the maximum value and a minimum value of $-458 \mathrm{mV}$ of sample coated with ceramic powder sample A. The electrode potential values were consistently high when compared with the uncoated sample. For the sample coated at $350^{\circ} \mathrm{C}$, the electrode potential value shows a maximum value of $-194 \mathrm{mV}$ and a minimum value of $-416 \mathrm{mV}$. The values are high when compared with that of the uncoated sample but low when compared with that of the transformer steel sheet coated with ceramic coating Y. the nobler the electrode potential value the higher the corrosion resistance. The range of electrode potential values for $300^{\circ} \mathrm{C}$ indicate, a higher corrosion resistance and this was observed in corrosion rate while $300^{\circ} \mathrm{C}$ had the best corrosion resistance.

\subsection{Effect of Different Temperatures of Coating on the Corrosion Rate of the Steel Coated with Ceramic Powder Y}

The steel coated at lower temperature $100^{\circ} \mathrm{C}-200^{\circ} \mathrm{C}$ when compared with that of higher temperature $250^{\circ} \mathrm{C}$ $400^{\circ} \mathrm{C}$ had a lower increase in initial weight. As the coating temperature increases the initial weight after coating increases. Because of the initial absorption of the solution by the ceramic coating, the determination of the rate of corrosion in the corrosion media was not easy to determine accurately. But the decrease in weight after the initial absorption can be discovered to vary with temperature.

\subsection{Steel Coated at $100^{\circ} \mathrm{C}$ with Ceramic Powder Y}

It was discovered that for the period of 30 days the sample coated at $100^{\circ} \mathrm{C}$ maintained a weight above the initial weight of the coated sample. This was largely due to the resistant of the ceramic coating to the corrosion and partly due to the absorptive characteristic of the ceramic material. There was gradual reduction in weight with respect to the initial weight after the first day of exposure.

The steel sheet coated at $100^{\circ} \mathrm{C}$ has the highest hardness values with respect to the initial hardness value of the uncoated steel (Table 2).

The electrode potential value of the coated steel was high compared with the uncoated sample, the highest value being $-128 \mathrm{mV}$ while the lowest value was $-453 \mathrm{mV}$. Experimental results have shown that higher positive values of electrode potential indicate higher resistance to corrosion rate [17]-[19].

\subsection{Steel Coated At $200^{\circ} \mathrm{C}$ with Ceramic Powder Y}

For the steel sheet coated at $200^{\circ} \mathrm{C}$ the rate of weight loss was gradual and consistently above the initial weight 
of the ceramic coated steel for the first 25 days of experimental work until it began to experience loss in weight. The rate of absorption by the sample after introducing it into the corrosion media was low when compared it with sample coated at $100^{\circ} \mathrm{C}$. This is consistent with expectation because of the increase in temperature involved.

The hardness value drops with reference to the sample coated at $100^{\circ} \mathrm{C}$. A critical analysis of this result shows that the surface coating at this temperature was harder than that of the sample coated at $100^{\circ} \mathrm{C}$. The sample coated at $100^{\circ} \mathrm{C}$ as a higher hardness value compared with sample at $200^{\circ} \mathrm{C}$ which shows a higher resistance hence a lower hardness value. Therefore it should be noted that the lower the hardness value, the higher the hardness of the ceramic coating.

With reference to Figure 5, the maximum value of $-110 \mathrm{mV}$ and a minimum value of $-456 \mathrm{mV}$ was observed throughout the 30 days. For the electrode potential, this value is also considerably high with reference to the uncoated sample and close to that of the sample coated at $100^{\circ} \mathrm{C}$.

\subsection{Steel Coated at $250^{\circ} \mathrm{C}$ with Ceramic Powder Y}

For the steel sheet coated at a temperature of $250^{\circ} \mathrm{C}$ the weight of the sample after 30 days was consistently above that of the initial weight of the ceramic coated steel at this temperature. This is largely due to the resistant of the ceramic coating to corrosion and also partly due to the absorptive characteristic of the ceramic material. The weight of the sample after coating rises than the sample coated at $100^{\circ} \mathrm{C}$ and $200^{\circ} \mathrm{C}$. This was due to the fact that at this temperature the adherence of the ceramic material to the steel sheet that was use increased.

The hardness values drop and indicates a higher hardness of the ceramic coating.

The electrode potential value also ranges from a maximum value of $-115 \mathrm{mV}$ to a minimum value of -428 $\mathrm{mV}$ which indicates a good resistance to the rate of corrosion than $200^{\circ} \mathrm{C}$.

\subsection{Steel Sheet Coated at $300^{\circ} \mathrm{C}$ with Ceramic Powder Y}

The adherence of the ceramic material to the steel sheet increases at this temperature of coating hence the increase in weight of the sample after the 1st day of exposure. The weight of the coated sample after 30 days of exposure was higher than the initial weight after coating. A higher value of weight difference than the other temperatures of coating was observed, hence a better coating. The highest resistance to corrosion was observed at this temperature (Figure 6). At this coating temperature there was a sharp drop in the hardness value and hence a corresponding increase in the hardness of the ceramic coating when compared to other coating temperatures used. The electrode potential values vary from a maximum value of $-114 \mathrm{mV}$ and a minimum value of $-420 \mathrm{mV}$. This give a narrower range when compared with other coating temperatures used. The electrode potential values were consistently nobler when compared with the uncoated sample.

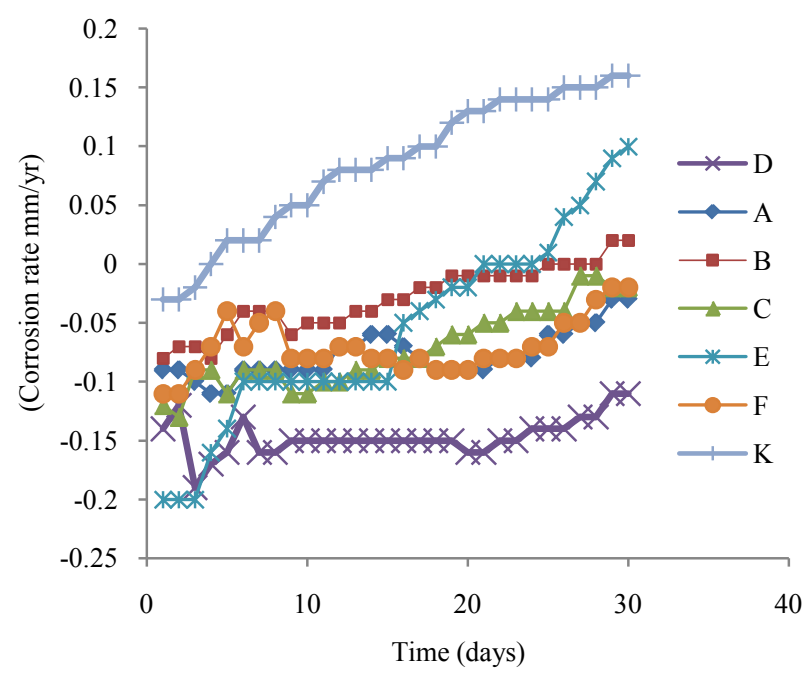

Figure 6. Corrosion rate of steels sheet coated with ceramic sample Y with uncoated sample. 


\subsection{Steel Sheet Coated at $350^{\circ} \mathrm{C}$ with Ceramic Material Ceramic Powder Y}

A decrease in the hardness of the sample was observed after coating, hence an increase in the hardness of the ceramic coating. It could be deduced that the weight of sample $\mathrm{E}$ was higher than that of the initial weight of the coating for the first 20 days (Figure 6). By comparing the weight of the sample before and after coating, it could also be discovered that the ceramic material that adhered to the steel sheet was high. But due to high temperature, after 20 days of exposure the ceramic material started peeling off. This increases the corrosion rate of the steel sheet. The electrode potential value falls with the range of $-128 \mathrm{mV}$ being the maximum value and a minimum value of $-458 \mathrm{mV}$.

\subsection{Steel Sheet Coated at $400^{\circ} \mathrm{C}$ with Ceramic Material Ceramic Powder Y}

By comparing the initial weight of ceramic powder $Y$ before coating and the final weight after coating it can be seen from the table that the ceramic material that adhered to the steel sheet reduces drastically. Actually, above $400^{\circ} \mathrm{C}$ ceramic coating of the steel sheet does not occur. The weight of the coated sample in the corrosion media was higher than that of the initial weight of the coated sample throughout the 30 days of observation.

\subsection{Effect of Different Temperatures of Coating on the Corrosion Rate of the Steel Coated with Ceramic Powder Z}

For the steel sheet coated with ceramic powder $\mathrm{Z}$, the initial temperatures at which coating took place was $250^{\circ} \mathrm{C}, 300^{\circ} \mathrm{C}$ and $350^{\circ} \mathrm{C}$. Below $250^{\circ} \mathrm{C}$, the coating of the steel sheet did not occur. Unlike the ceramic powder $\mathrm{Y}$, the adherence of the ceramic material to the steel sheet is not much. But also unlike the ceramic material labelled as ceramic powder $\mathrm{Y}$, the entire surface of the material before and after coating maintain a uniform blackish colour throughout the period of observation.

\subsection{Steel Sheet Coated at $250^{\circ} \mathrm{C}$ with Ceramic Powder $\mathrm{Z}$}

The weight of the coated steel sheet increased for the first 8 days of exposure in the corrosion media after which the weight started dropping below that of the initial weight after coating. This was due to the absorptive characteristic of the ceramic materials. By carefully considering the column for the corrosion rate it would be discovered that the rate of corrosion was rapid (Figure 7).

The electrode potential value shows a maximum value of $-194 \mathrm{mV}$ and a minimum value of $-416 \mathrm{mV}$. The values are high when compared with that of the uncoated samples which show a maximum of $-525 \mathrm{mV}$ and a minimum of $-931 \mathrm{mV}$ (Figure 8). But the value is low when compared with that of the steel sheet coated with ceramic powder $\mathrm{Y}$.

\subsection{Steel Sheet Coated at $300^{\circ} \mathrm{C}$ with Ceramic Powder $\mathrm{Z}$}

The weight of the ceramic material that adheres to the steel sheet at this temperature of coating is almost similar to that of the sample coated at $250^{\circ} \mathrm{C}$. For the first 12 days, it was observed that the weight of the sample was increased (Figure 7) after which the material begins to show significant increase in the rate of corrosion. The electrode potential value shows a minimum value of $-125 \mathrm{mV}$ which is higher than of the sample coated at $250^{\circ} \mathrm{C}(-416 \mathrm{mV})$. This coating temperature is a better coating temperature in ceramic powder $\mathrm{Z}$ coating than the coating temperature at $250^{\circ} \mathrm{C}$.

\subsection{Steel Sheet Coated at $350^{\circ} \mathrm{C}$ with Ceramic Powder Z}

It was observed that the weight of the sample within the first 12 days of exposure was high than the initial weight after coating. After the first days of exposure the rate of corrosion was rapid. At this temperature the maximum electrode potential was $-146 \mathrm{mV}$ while the minimum value was $-629 \mathrm{mV}$.

\subsection{Steel Sheet Coated at $400^{\circ} \mathrm{C}$ with Ceramic Powder $\mathrm{Z}$}

It was observed that the initial weight of the sample before and after coating reveals that at this temperature of coating only a few particles of the ceramic material actually adhere to the steel sheet. After the first day of 


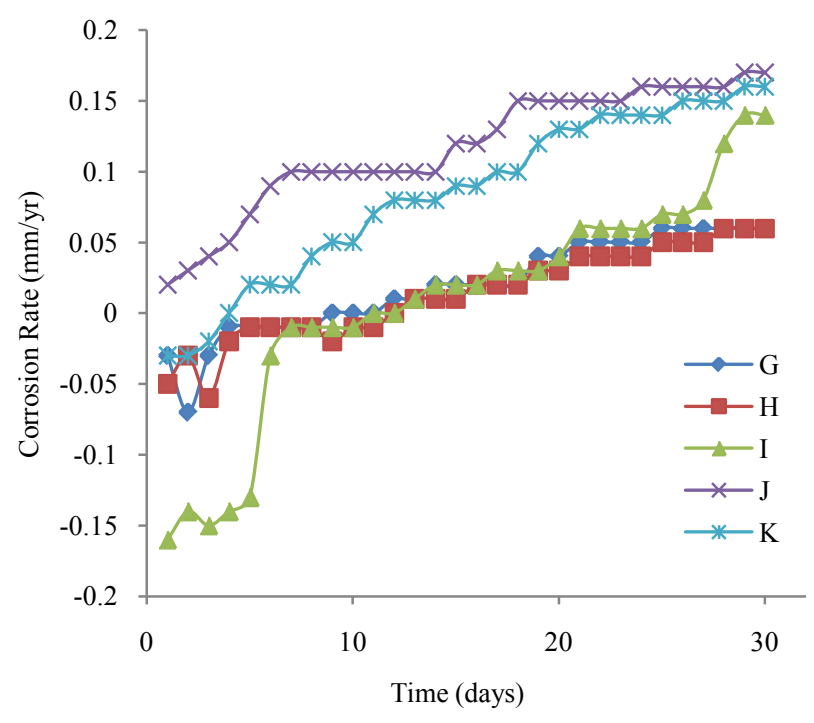

Figure 7. Corrosion rate of ceramic powder $\mathrm{Z}$ coated sample and uncoated steel in $0.5 \mathrm{M} \mathrm{NaCl}$.

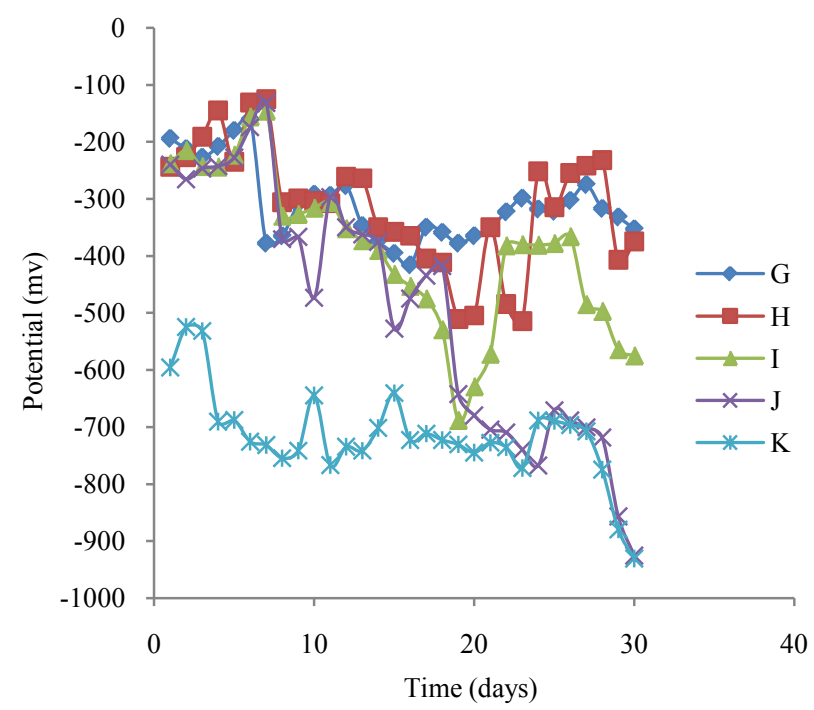

Figure 8. The graph of potential with time of steel sples a coated with ceramic sample $\mathrm{Z}$ with uncoated sample in $0.5 \mathrm{M}$ $\mathrm{NaCl}$ solution.

exposure this particles were washed away by the corrosion media. Hence the corrosion rate was high. The coating process did not adhere enough at this temperature.

\section{Conclusions}

The research work carried out on the effect of different coating temperatures on the corrosion behaviour of ceramic coated steels led to the following conclusions:

1) A new locally sourced ceramic coated substrate material which can serve as a semiconductor in electrical appliances was produced.

2) Results showed that finer samples of ceramic materials increased the ease of coating.

3) The rate of corrosion depended on the coating temperatures.

4) For ceramic powder $Y$, considering the corrosion result, the best coating temperature occurred at $300^{\circ} \mathrm{C}$. 
5) By comparing the results given by the two types of ceramic materials that were used in the course of the experimental work, the ceramic powder $Z$ gave a better result in terms of high resistance to the flow of current and to corrosion. The optimum value for resistance to current was observed for ceramic powder $\mathrm{Z}$ and $\mathrm{Y}$ at coating temperature of $300^{\circ} \mathrm{C}$.

\section{Acknowledgements}

Regional Initiative in Science and Education (RISE), Science Initiative Group, Einstein Drive USA.

\section{References}

[1] Kurt, H.S. (1996) Metallurgical and Ceramic Protective Coatings, Printed in Great Britain. St. Edmundsbury Press, Vol. 1, 36-39, 112-1113, 153, 303-305, 317-330.

[2] Clive, H. (2006) Taylor and Francis Group 6000 Broken Sound Parkway NW. Coatings Technology Handbook CRC Press, Vol. 1, 26-38; 102-1-102-8.

[3] Chatha, S., Sidhu, H. and Sidhu, B. (2012) Characterization and Corrosion-Erosion Behaviour of Carbide Based Thermal Spray Coatings. Journal of Minerals and Materials Characterization and Engineering, 11, 569-586. http://dx.doi.org/10.4236/jmmce.2012.116041

[4] Khanna, A., Kumari, S., Kanungo, S. and Gasser, A. (2009) Hard Coatings Based on Thermal Spray and Laser Cladding. International Journal of Refractory Metals and Hard Materials, 27, 485-491. http://dx.doi.org/10.1016/j.ijrmhm.2008.09.017

[5] Roy, M., Pauschitz, A., Polak, R. and Franek, F. (2006) Comparative Evaluation of Ambient Temperature Friction Behaviour of Thermal Sprayed Cr3C2-25(Ni20Cr) Coatings with Conventional and Nano-Crystalline Grains. Journal of Tribology International, 39, 29-38. http://dx.doi.org/10.1016/j.triboint.2004.11.009

[6] Robert, V.D., Lasantha, T.V., Anil, V., Tapan, K.R. and Sarbajit, B. (2013) Graphene Nano Composite Coatings for Protecting Low Alloy Steels from Corrosion. American Ceramic Society Bulletin, 92, 18-24. http://ceramics.org/wp-content/uploads/2013/05/bulletin_jun-jul13

[7] Kingery, W.D. and Bowen, H.K. (1960) Introduction to Ceramics. 4th-5th Edition, Wiley, New York.

[8] Van, N.R. (1963) High Temperature Inorganic Coatings. 7-8.

[9] Philipee, M. (2002) Corrosion Mechanisms in Theory and Practice. 23-25, ISBN-13: 978-0824706661.

[10] Sahraoui, T., Fenineche, N.-E., Montavon, G. and Coddet, C. (2003) Structure and Wear Behavior of VOF Sprayed Cr3C2-NiCr and WC-Co Coatings. Materials \& Design, 24, 309-313. http://dx.doi.org/10.1016/S0261-3069(03)00059-1

[11] Lih, W.-C., Yang, S., Su, C., Huang, S., Hsu, I. and Leu, M. (2000) Effects of Process Parameters on Molten Particle Speed and Surface Temperature and the Properties of HVOF CrC/NiCr Coatings. Surface and Coatings Technology, 133-134, 54-60. http://dx.doi.org/10.1016/S0257-8972(00)00873-2

[12] Sidhu, H., Sidhu, B. and Prakash, S. (2006) The Role of HVOF Coatings in Improving Hot Corrosion Resistance of ASTM-SA210 GrA1 Steel in the Presence of $\mathrm{Na}_{2} \mathrm{SO}_{4}-\mathrm{V}_{2} \mathrm{O}_{5}$ Salt Deposits. Surface and Coatings Technology, 200, 5386-5394. http://dx.doi.org/10.1016/j.surfcoat.2005.07.008

[13] Sidhu, T., Prakash, S. and Agrawal, R. (2006) Characterizations of HVOF Sprayed NiCrBSi Coatings on Ni- and Fe-Based Superalloys and Evaluation of Cyclic Oxidation Behaviour of Some Ni Based Superalloys in Molten Salt Environment. Journal of Thin Solids Film, 515, 95-105. http://dx.doi.org/10.1016/j.tsf.2005.12.041

[14] Sidhu, B. and Prakash, S. (2006) Studies on the Behaviour of Stellite-6 as Plasma Sprayed and Laser Remelted Coatings in Molten Salt Environment at $900^{\circ} \mathrm{C}$ under Cyclic Conditions. Journal of Materials Processing Technology, 172, 52-63. http://dx.doi.org/10.1016/j.jmatprotec.2005.08.018

[15] Guilemany, J., Fernández, J., Delgado, J., Benedetti, A. and Climent, F. (2002) Effects of Thickness Coating on the Electrochemical Behaviour of Thermal Spray Cr3C2-NiCr Coatings. Surface and Coatings Technology, 153, 107-113. http://dx.doi.org/10.1016/S0257-8972(01)01679-6

[16] Verdon, C., Karimi, A. and Martin, J.-L. (1998) Study of High Velocity Oxy-Fuel Thermally Sprayed Tungsten Carbide Based Coatings. Part 1: Microstructures. Materials Science and Engineering: A, 246, 11-14.

[17] Chatterjee, U.K., Bose, S.K. and Roy, S.K. (2001) Environmental Degradation of Metals. Marcel Dekker Inc., 23-44, $375-408$.

[18] Olaseinde, O.A., Cornish, L.A., Merwe, J.V. and Olubambi, P.A. (2011) Electrochemical Behaviour of 2101 DSS with Ruthenium and 316 SS. The Proceedings of the 18th International Corrosion Congress, Perth, 1541-1548. 
[19] Olaseinde, O.A., Merwe, J.V. and Cornish, L. (2014) Characterization and Corrosion Behaviour of Selected Duplex Stainless Steels in Acidic and Acidic-Chloride Solution. Advances in Chemical Engineering and Science, 4, 89-93. http://dx.doi.org/10.4236/aces.2014.41012 